\title{
THE UPTAKE OF RADIOACTIVE PHOSPHORUS INTO THE ACID-SOLUBLE COMPOUNDS OF GUINEA-PIG LIVER DURING ANAPHYLACTIC REAGTION
}

\author{
MITSUYASU KITAMURA \\ Department of Pharmacology, Okayama University Medical School, Okayama \\ Received for publication January 18, 1966
}

Prcviously, it was reported that in in vivo anaphylaxis there were observed a fall in adenosine triphosphate (ATP) level and a rise in adenosine monophosphate (AMP) level of guinea-pig liver, but no changes in the values of ATP and other adenine nucleotides in the lung of in vivo shock. However, the fall of ATP in liver was not observable in in vitro anaphylactic reaction (1).

The fall of ATP lcvel in tissucs has been also reported in the animals treated with certain drugs $(2-5)$ or with $\mathrm{X}$-ray irradiation $(6,7)$. In the latter case, aside from a fall of ATP level, a significant decrease is shown in the $\mathrm{P}^{32}$ incorporation into nucleotide fraction of spleen and thymus in the mice transplantcd with mammary carcinoma.

The present paper describes the result of an investigation on the adenine nucleotide contents and on the $\mathrm{P}^{32}$ incorporation into the nucleotides of guinea-pig liver in in vivo anaphylaxis, as determined by the ion exchange chromatographic method.

The experiments were also conducted on the animals trcated with histamine, since histamine is known as a mediator in anaphylaxis in guinea pig, producing anoxia by constricting bronchial muscle, which is a phenomenon practically undistinguishable from anaphylactic shock.

\section{METHODS}

Sensitization: Male guinea pig (about $270 \mathrm{~g}$ ) were sensitized by injecting $1 \mathrm{ml}$ each of $10 \%$ solution of egg albumin subcutaneously on the back as well as intraperitoneally, and used for experiments 3-6 weeks later.

Administration of $P^{32}$ and preparation of acid soluble fraction: $\mathrm{H}_{3} \mathrm{P}^{32} \mathrm{O}_{4}$ (ortho phosphoric type), a commercial product from the Japan Radio Isotope Association, was diluted with potassium phosphate buffer ( $\mathrm{pH} 7.4$ ), boiled for one hour, and then the solution was adjusted to $50 \mu \mathrm{C} / \mathrm{ml}$ with physiological saline solution.

Sensitized guinea pigs were injected with $50 \mu \mathrm{C}$ of $\mathrm{P}^{32}$ intraperitoneally and one hour later challenged with antigen by the cardiac injcction of a physiological saline solution containing egg albumin $2 \mathrm{mg}$ per $100 \mathrm{~g}$ body weight. Immediately after the terminal breathing, which occurred about 5 minutes later, the animals were bled and liver was excised as quickly as possible and put in acetonc-dry ice for freezing. 
To about $2 \mathrm{~g}$ of the tissue thrce volumes of cold $0.6 \mathrm{~N}$ perchloric acid were added and the mixture was homogenized in the Potter-Elvehjem glass homogenizer. After centrifugation the precipitate was washed with $0.2 \mathrm{~N}$ perchloric acid, and the combined supernatant was neutralized with $20 \% \mathrm{KOH}$, which resulted in the precipitation of potassium pcrchlorate. After filtration, the supernatant served as the material for the ion exchange chromatographic analysis.

As control, non-sensitized animals were similarly treated with antigen, and 5 minutes latcr benumbed by a blow on the back of head and bled. Each set of experiment on a pair of control and shocked animal was performed on the same day.

In the experiments of histamine shock, guinea pigs were injected with histamine dihydrochloride $1 \mathrm{mg} / \mathrm{kg}$ by the cardiac puncture. All the animals exhibited severe shock symptoms with marked asphyxia, breathing terminating within 5 minutes. Im-

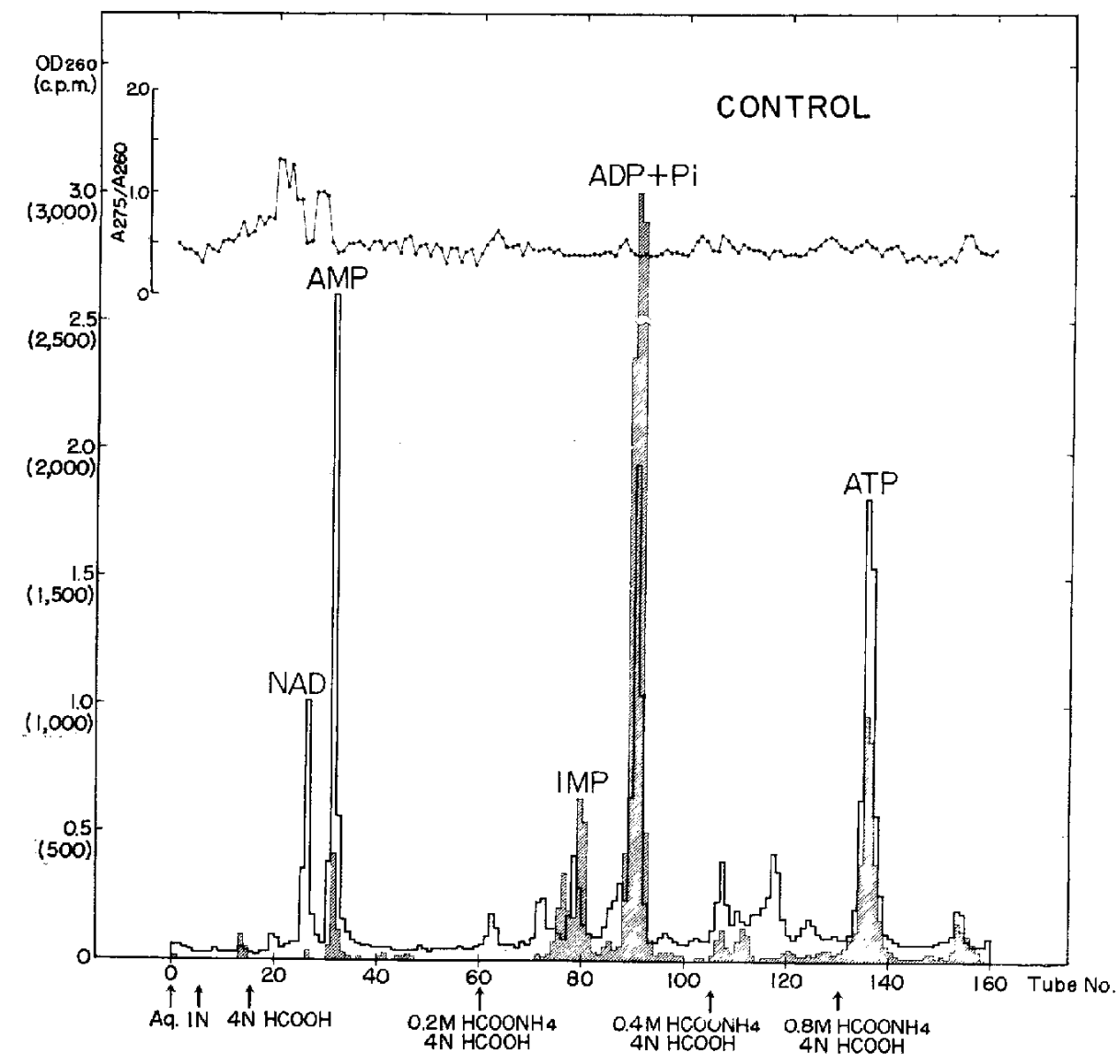

FIG. 1. Chromatographic separation of nucleotides of the liver of the normal guinea pig. An acid soluble fraction was run through a column of Dowex 1 (X 10$)$ in the formate form and the concentration of formic acid and ammonium formate as indicated. White column represents $O D$ at $260 \mathrm{~m} / \mu$ and hatched column the radioactivity of $\mathrm{P}^{32}$. IMP : inosine monophosphate; as for other abbreviations see text. Experimental conditions are given in the text. 
mediately after the terminal breathing, liver was excised and similarly treated as mentioned above.

Ion exchange chromatography: The methods used were principally the same as reported in the previous paper (1), except that the size of the Dowex column was of $1.0 \times 40 \mathrm{~cm}$, slightly larger diameter, for the purpose to obtain more accurate values of ATP content. Gradient elution was carried out by the formate system. The absorbancy of each fraction was determined at $260 \mathrm{~m} \mu$ as well as at $275 \mathrm{~m} \mu$, where the ratio of OD (optical density) at $275 \mathrm{~m} \mu$ versus $\mathrm{OD}$ at $260 \mathrm{~m} / 2$ was used as the basis for the identification of the base component of nucleotides. Nicotinamide adenine dinucleotide (NAD) was also determined at $325 \mathrm{~m} \mu$ after the addition of $\mathrm{KCN}$.

Determination of $P^{32}$ radioactivity: One $\mathrm{ml}$ of eluting solution was dried in the sample planchet, and the radioactivity of $\mathbf{P}^{32}$ was determined by Geiger-Müller counter.

\section{RESULTS}

1. The mucleotide contents and $P^{32}$ incorporated into the nucleotides of guinea-pig liver in anaphylactic shock

Nucleotide contents and $\mathrm{P}^{31}$ incorporation were determined by the $O D$ at $260 \mathrm{~m} \mu$ and the radioactivity of $\mathrm{P}^{32}$ by means of Dowex 1 chromatography with the acid soluble

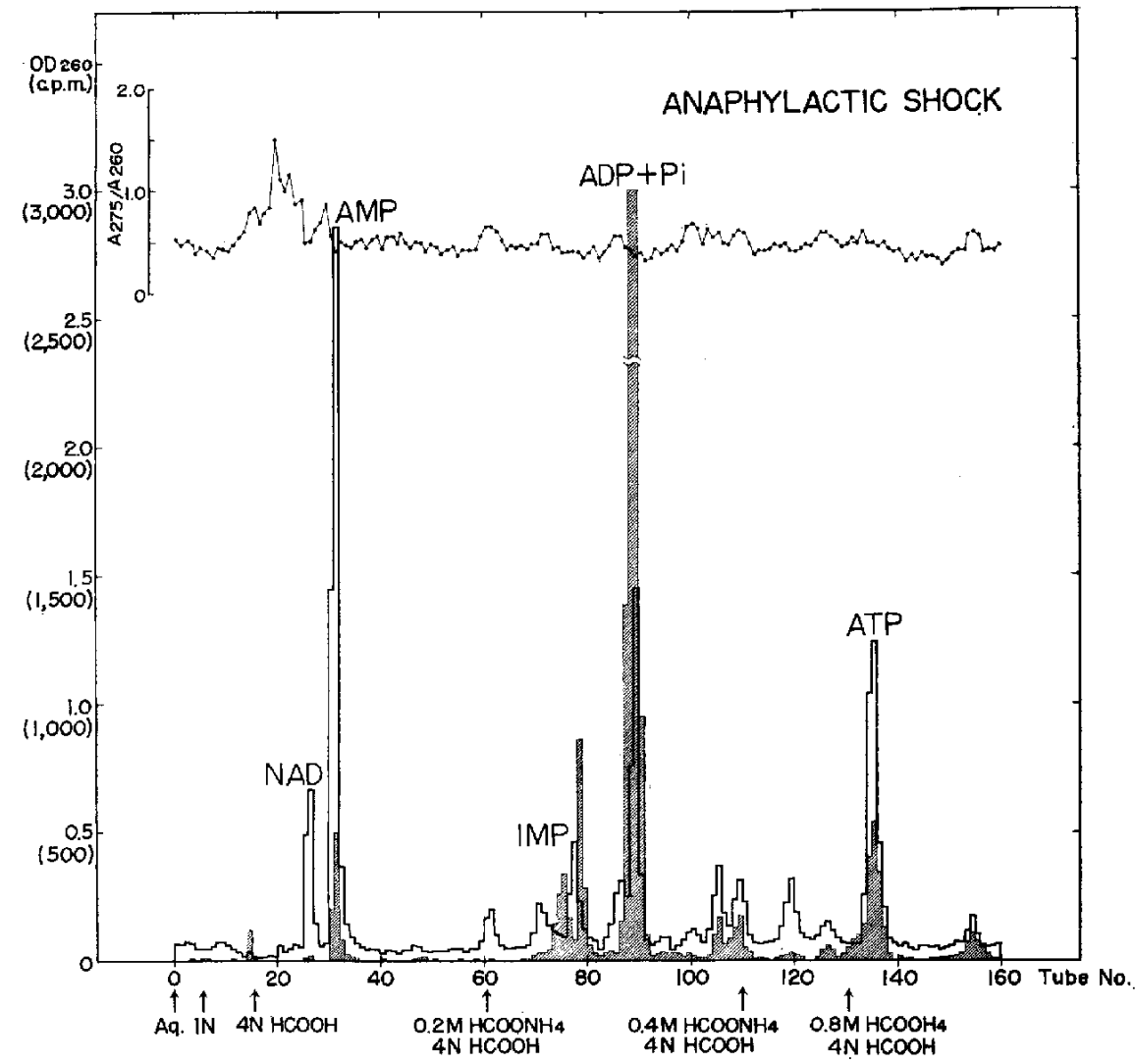

FIC. 2. Chromatographic separation of nucleotide of the liver of an anaphylactically shocked guinea pig. Same procedure as in Fig. 1. 
fraction extracted from the livers of guinea pigs both in anaphylactic shock and in the control group. As illustrated in Figs. 1 and 2, there can be observed neither disappearance of the peak of nucleotides nor appearance of any new peak in the liver of anaphylactic shock. However, quantitative determination revealed some lowering of the peak of ATP.

TABLE 1. Gontent $(\mathrm{OD} / \mathrm{g})$ and incorporated $\mathrm{P}^{32}$ (c.p.m./g) of adcnine nucleotides in the liver of anaphylactically shocked guinea pigs.

\begin{tabular}{|c|c|c|c|c|}
\hline & \multicolumn{2}{|c|}{ Control } & \multicolumn{2}{|c|}{ Shocked animal } \\
\hline & $\mathrm{OD} / \mathrm{g}$ & c.p.m./g & $\mathrm{OD} / \mathrm{g}$ & c.p.m./g \\
\hline $\begin{array}{r}\text { Expt. } 1 \\
\text { Total }\end{array}$ & 159.9 & 93,001 & 143.6 & 51,072 \\
\hline NAD & 7.7 & 129 & 7.5 & 5.5 \\
\hline AMP & 26.7 & 2,174 & 26.7 & 1,820 \\
\hline $\mathrm{ADP}+\mathrm{Pi}$ & 20.9 & 36,394 & 19.3 & 28,407 \\
\hline ATP & 15.8 & 6,054 & 13.6 & 3,604 \\
\hline $\begin{array}{r}\text { Expt. } 2 \\
\text { Total }\end{array}$ & 131.1 & 59,952 & 127.9 & 63,270 \\
\hline NAD & 8.0 & 42 & 7.6 & 84 \\
\hline AMP & 23.3 & 1,858 & 25.4 & 2,011 \\
\hline $\mathrm{ADP}+\mathrm{Pi}$ & 25.9 & 39,289 & 18.6 & 38,789 \\
\hline ATP & 14.7 & 6,437 & 10.3 & 4,129 \\
\hline $\begin{array}{r}\text { Expt. } 3 \\
\text { Total }\end{array}$ & 120.5 & 65,313 & 121.2 & 50,085 \\
\hline NAD & 4.2 & 8 & 3.5 & 8 \\
\hline AMP & 28.9 & 2,773 & 29.5 & 2,353 \\
\hline $\mathrm{ADP} \vdash \mathrm{Pi}$ & 13.6 & 50,255 & 14.3 & 31,995 \\
\hline ATP & 8.1 & 3,242 & 7.8 & 2,482 \\
\hline $\begin{array}{r}\text { Expt. } 4 \\
\text { Total }\end{array}$ & 136.6 & 66,938 & 115.2 & 62,937 \\
\hline NAD & 5.1 & 60 & 6.2 & 97 \\
\hline AMP & 29.3 & 2,857 & 20.6 & 2,129 \\
\hline $\mathrm{ADP}+\mathrm{Pi}$ & 20.4 & 45,643 & 15.9 & 38,318 \\
\hline ATP & 14.4 & 7,048 & 9.1 & 4,724 \\
\hline $\begin{array}{r}\text { Expt. } 5 \\
\text { Total }\end{array}$ & 129.8 & 86,246 & 118.0 & 86,108 \\
\hline NAD & 8.1 & 167 & 5.5 & 103 \\
\hline AMP & 18.6 & 2,959 & 24.3 & 4,011 \\
\hline $\mathrm{ADP}+\mathbf{P i}$ & 24.6 & 53,333 & 17.0 & 55,489 \\
\hline ATP & 25.0 & 14,167 & 15.9 & 7,694 \\
\hline $\begin{array}{c}\text { Average } \\
\text { Total }\end{array}$ & 135.6 & .61 & 123.2 & .17 \\
\hline NAD & 6.6 & .82 & 6.0 & .79 \\
\hline AMP & 25.4 & .84 & 25.5 & .48 \\
\hline $\mathrm{ADP}+\mathbf{P i}$ & 21.1 & .15 & 16.9 & .87 \\
\hline ATP & 15.6 & & 11.6 & .47 \\
\hline
\end{tabular}

Table 1 shows the results of five experiments, and the average values of the $\mathrm{OD}$ at $260 \mathrm{~m} \mu$ in four adenine nucleotides -NAD, AMP, ADP and ATP--per $1 \mathrm{~g}$ tissue of the liver. The reason for the inability to obtain the average count of incorporated $\mathrm{P}^{32}$ lies in the fact that no uniform counts can be taken from different sets of experiment becausc of the short halflife of $\mathrm{P}^{32}$. Despite this the $\mathrm{OD}$ and $\mathrm{P}^{32}$ of ATP fraction in the anaphylactically shocked animals seem to be decreased. The variations of the means are statistically not significant, but this is probably duc to varying ATP lcvels dependent upon experimental factors such as conditions of feeding, and seasonal changes, etc. Therefore, the values of a pair each from the experimental and the control animals were compared. Both the level of ATP and $\mathrm{P}^{32}$ uptake are invariably decreased in the shocked animals as shown in Table 2, in which means of the values from individual experimental groups are presented as per-
TABI,E 2. Content $(\mathrm{OD} / \mathrm{g})$ and in- corporated $\mathrm{P}^{32}$ (c.p.m./g) of adenine nucleotides in the liver of anaphylactically shocked guinea pigs, as percent of corresponding controls.

\begin{tabular}{lrr}
\hline & \multicolumn{1}{c}{ Mean as $\%$ of control } \\
& \multicolumn{1}{c}{ OD } & \multicolumn{1}{c}{$\mathrm{P}^{32}$} \\
\hline Total & $93 \pm 2.9$ & $86 \pm 9.2$ \\
NAD & $92 \pm 9.1$ & $113 \pm 29.7$ \\
AMP & $102 \pm 9.7$ & $97 \pm 11.0$ \\
ADP $+\mathrm{Pi}$ & $83_{ \pm 6.8}$ & $86 \pm 7.9$ \\
ATP & $76 \pm 6.7$ & $64 \pm 3.8$ \\
\hline
\end{tabular}


TABLF. 3. Content (OD/g) and incorporated $P^{212}$ (c.p.m/g) of adenine nucleotides in the liver of histamine-shocked guinea-pig.

\begin{tabular}{|c|c|c|c|c|}
\hline & \multicolumn{2}{|c|}{ Control } & \multicolumn{2}{|c|}{ Shocked animal } \\
\hline & $\mathrm{OD} / \mathrm{g}$ & c.p.m./g & ODig & c.p.m./g \\
\hline $\begin{array}{l}\text { Expt. I } \\
\text { Total }\end{array}$ & 124.6 & 190,322 & 116.9 & 139,599 \\
\hline $\mathrm{NAD}$ & 4.0 & 270 & 5.7 & 218 \\
\hline $\mathrm{AMP}$ & 24.3 & 6,764 & 23.4 & 4,782 \\
\hline $\mathrm{ADP} \perp \mathrm{Pi}$ & 22.9 & 121,070 & 18.4 & 79,353 \\
\hline АTP & 12.9 & 18,932 & 12.6 & 13,452 \\
\hline $\begin{array}{r}\text { Expt. } 2 \\
\text { Total }\end{array}$ & 132.9 & 167,872 & 141.6 & 113,772 \\
\hline NAD & 6.5 & 239 & 5.8 & 114 \\
\hline AMP & 23.3 & 4,365 & 25.3 & 3,582 \\
\hline $\mathrm{ADP}+\mathrm{Pi}$ & 24.3 & 92,619 & 23.1 & 58,421 \\
\hline ATP & 12.8 & 16,142 & 14.1 & 10,629 \\
\hline $\begin{array}{r}\text { Fxpt. } 3 \\
\text { Total }\end{array}$ & 130.4 & 106,020 & 130.1 & 105,183 \\
\hline NAD & 4.2 & 119 & 4.9 & 190 \\
\hline AMP & 24.4 & 4,997 & 24.5 & 5,810 \\
\hline $\mathrm{ADP}+\mathrm{Pi}$ & 25.5 & 61,000 & 19.1 & 62,325 \\
\hline ATP & 17.2 & 9,792 & 14.1 & 7,639 \\
\hline $\begin{array}{r}\text { Expt. } 4 \\
\text { Total }\end{array}$ & 136.2 & 61,275 & 139.4 & 100,606 \\
\hline $\mathrm{NAD}$ & 3.9 & 20 & 8.9 & 45 \\
\hline AMP & 25.7 & 1,759 & 24.4 & 1,992 \\
\hline $\mathrm{ADP}-\mathrm{Pi}$ & 26.6 & 34,153 & 22.3 & 53,373 \\
\hline A'TP & 18.2 & 8,160 & 13.0 & 8,836 \\
\hline $\begin{array}{r}\text { Expt. } 5 \\
\text { Total }\end{array}$ & 129.7 & 115,680 & 132.8 & 113,005 \\
\hline NAD & 7.7 & 129 & 7.0 & 124 \\
\hline $\mathrm{AMP}$ & 21.8 & 3,208 & 24.6 & 3,340 \\
\hline $\mathrm{ADP}+\mathrm{Pi}$ & 22.0 & 67,376 & 19.6 & 65,874 \\
\hline ATP & 12.2 & 10,233 & 12.8 & 10,720 \\
\hline $\begin{array}{c}\text { Average } \\
\text { Total }\end{array}$ & 130.8 & 1.92 & 132.2 & 2.94 \\
\hline $\mathrm{NAD}$ & 5.3 & 0.78 & 6.5 & 0.75 \\
\hline $\mathrm{AMD}$ & 23.9 & 0.21 & 24.4 & 0.10 \\
\hline $\mathrm{ADP}, \mathrm{Pi}$ & $24.3=$ & 0.26 & 20.5 & 0.29 \\
\hline $\mathrm{ATP}$ & 14.7 & 0.39 & 13.3 & 0.10 \\
\hline
\end{tabular}

TABIE 4. Content $(\mathrm{OD} / \mathrm{g})$ and incorporated $\mathrm{P}^{32}$ (c.p.m./g) of adenine nucleotides in the liver of histamine-shocked guinca pigs, as percent of corresponding controls.

\begin{tabular}{lrr}
\hline & \multicolumn{2}{c}{ Mean as $\%$ of control } \\
& OD & \multicolumn{1}{c}{$\mathrm{P}^{32}$} \\
Total & $101 \pm 1.9$ & $107 \pm 17.2$ \\
NAD & $133 \pm 25.5$ & $122 \pm 30.3$ \\
AMP & $103 \pm 3.5$ & $97 \pm 8.9$ \\
ADP +Pi & $85 \pm 3.5$ & $99 \pm 16.8$ \\
ATP & $93 \pm 6.4$ & $86 \pm 8.8$ \\
\hline
\end{tabular}

cent of the control. Thus, mean percentages of the content of ATP and the amount of $\mathrm{P}^{32}$ incorporated into ATP fraction in the anaphylactically shocked liver were $76 \pm$ $6.7 \%$ and $64 \pm 3.8 \%$, respectively, of corresponding controls. Those of ADP were $83 \pm 6.8 \%$ and $86 \pm 7.9 \%$ respectively, which are slightly decreased.

2. The nucleotide contents and $P^{32}$ incorporaled into the nucleotides of guinea-pig liver in histamine shock

In order to study the effect of anoxia, anticipated in anaphylactic shock, on the liver ATP level, the ATP content and the $\mathrm{P}^{32}$-uptake were examined with guinea pigs shocked by histamine under the same experimental conditions.

Table 3 shows data of five individual experimental groups, with average values of the OD at $260 \mathrm{~m} / \mu$ for four adenine nucleotides per $1 \mathrm{~g}$ tissue. For the samc reason as described before, mean from five experimental groups are given percent of

corresponding controls in Table 4.

Mean percentages of ATP content and incorporated $\mathrm{P}^{32}$ in ATP fraction in the histamine-shocked liver were found to be $93 \pm 6.4 \%$ and $86 \pm 8.8 \%$, respectively, of corresponding controls, and those of ADP were $85 \pm 3.5 \%$ and $99 \pm 16.8 \%$. 


\section{DISGUSSION}

In comparing one pair each from the experimental and the control animals, it has been found that the level of ATP always tends to decrease in the guinea-pig liver after the animal was subjected to anaphylactic shock. The valuc of the optical density at $260 \mathrm{~m} \%$ from test animals was $76 \pm 6.7 \%$ of that from the control. The incorporation of $P^{32}$ into ATP fraction likewise distinctly decreased in anaphylactically shocked animals, showing a value of $64 \pm 3.8 \%$ of the control. While a dccrease in the ATP level was observed along with an increase in AMP as reported in the previous paper (1), there was no distinct difference of the AMP contents in the present experiment. It is noteworthy that the decrease was observed rather in the ADP contents as well as in the amount of $\mathrm{P}^{32}$ incorporated into ADP fraction. This seems to be due to a slight modification of the experimental methods. The advantage lies in the use of a slightly bigger diameter of the column in ion exchange chromatography whereby the time of run is shortened considerably, thus minimizing degradation of ATP during the chromatographic procedurcs and enabling us to obtain a larger value of ATP.

Comparison was made between nucleotide contents and the incorporation of $\mathrm{P}^{32}$ in animals shocked with histamine. and those in anaphylactic shock for the purpose to see whether or not anoxia caused by the constricting effect of this amine on the bronchial muscles would decrease the ATP contents in the liver tissue. However, it was demonstrated that the extent of decrease in both the ATP level and the $\mathrm{P}^{32}$ incorporation was lesser in histamine shock than in anaphylactic shock. This suggests that the fall in the ATP level as observable in anaphylactic shock is elicited by some other more important factor(s) than anoxia alonc because the severity of asphyxia in the histamine shock was similar in the anaphylactic shock.

When a comparison is made between the results from anaphylaxis and those in other experiments, the simultaneous decrease of ATP and ADP observed in the present experiment resembles closely the results in the splcen and thymus of rats subjected to total body irradiation with $\mathrm{X}$-rays $(6,7)$. On the contrary, the administration of fever producing substances (2) or reserpine (3-5) shows a fall in the $\Lambda T P$ level with a simultaneous elevation of $\mathrm{ADP}$, indicating a marked decrease in the ratio of $\mathrm{ATP} / \mathrm{ADP}$.

Concerning the mechanism of a fall in ATP level as observed in anaphylaxis, the author suggested in the previous report (1) that it seems to be a decreased efficiency of ATP-synthesis resulting from an inhibition of mitochondrial oxidative phosphorylation by the mechanism presumably related to the circulating blood, since the decrease in ATP content was observed only in the in vivo experiment and not in the in vitro. Further study is required for the elucidation of this problem, especially by the biochemical method.

\section{SUMMARY}

1. Adenine nucleotide contents and $\mathrm{P}^{32}$ uptake into the nuclcotides of guinea-pig liver were determined by chromatographic method, and their changes in anaphylactic and histamine shock were followed. 
2. In both reactions, there was a fall in the $A T P$ level, which was more marked in anaphylaxis than in histamine shock. Mean percentage of the content of ATP and the amount of $\mathrm{P}^{32}$ incorporated into ATP fraction in the anaphylactically shocked liver were $76 \pm 6.7 \%$ and $64 \pm 3.8 \%$, respectively, of corresponding controls and those of ADP were $83 \pm 6.8 \%$ and $86 \pm 7.9 \%$, which are slightly decreased.

3. There were qualitative changes in the patterns of nucleotides in neither anaphylactic nor histamine shock.

Acknowledgement : I wish to thank Prof. H. Yamasaki and Assistant Prof. S. Muraoka in this laboratory for their guidance and criticism in this work.

\section{REFERENCES}

1) Kitamura, M. : Trfis Journat. 15, 135 (1965)

2) Mor, M.A.D. : Biochim. biophys. acta 44, 13 (1960)

3) Kirpekar, S.M. And Lewis, J.J. : Brit. J. Pharmacol. 14, 40 (1959)

4) KirPFKAR, S.M. AND LEWIS, J.J. : Ibid. 15, 175 (1960)

5) Kavl, C.L. and Lewis, J.J. : J. Pharmacol. 140, 111 (1963)

6) BeKKuM, D.W.V.: Biochim. biophys. acta 25, 487 (1957)

7) Salmon, R.J., Lokf., M.K., Mossfr, D.G. nNo Marvin, J.F. : Cancer Res. 20, 292 (1960) 